\title{
Evaluating clinical and prognostic implications of Glypican-3 in hepatocellular carcinoma
}

\author{
Ahmed Omar Kaseb ${ }^{1}$, Manal Hassan ${ }^{1}$, Sahin Lacin ${ }^{1,3, *}$, Reham Abdel-Wahab ${ }^{1,4, *}$, \\ Hesham M. Amin², Ahmed Shalaby ${ }^{1}$, Robert A. Wolff ${ }^{1}$, James Yao', Asif Rashid², \\ Bharathi Vennapusa ${ }^{5}$, Janine Feng ${ }^{5}$, Toshihiko Ohtomo ${ }^{6}$ \\ ${ }^{1}$ Department of Gastrointestinal Medical Oncology, The University of Texas MD Anderson Cancer Center, Houston, Texas, USA \\ ${ }^{2}$ Division of Pathology, The University of Texas MD Anderson Cancer Center, Houston, Texas, USA \\ ${ }^{3}$ Department of Medical Oncology, Hacettepe University, Medical Faculty, Ankara, Turkey \\ ${ }^{4}$ Department of Clinical Oncology, Assiut University Hospital, Assiut, Egypt \\ ${ }^{5}$ Ventana Medical Systems, Inc., Tucson, Arizona, USA \\ ${ }^{6}$ Chugai Pharmaceutical Co., LTD., Tokyo, Japan \\ *These authors contributed equally to this work
}

Correspondence to: Ahmed Omar Kaseb, email: akaseb@mdanderson.org

Keywords: hepatocellular carcinoma, glypican-3, immunohistochemistry

Received: June 16, 2016 Accepted: September 05, $2016 \quad$ Published: September 16, 2016

\section{ABSTRACT}

Hepatocellular carcinoma (HCC) is one of the most deadly cancers worldwide. In patients with $\mathrm{HCC}$, histopathogical differentiation is an important indicator of prognosis; however, because determination of HCC differentiation is difficult, the recently described immunohistochemical (IHC) marker glypican3 (GPC3) might assist in HCC prognostication.The goal of our study was to investigate GPC3's IHC staining pattern and define the relationship between its expression and patients' clinicopathologic features and overall survival. We retrieved clinical parameters from 101 pathologically diagnosed HCC patients' medical records and classified these patients into 4 clinical score categories (0-3) based on increasing GPC3 staining intensity and the percentage of stained tumor cells in their resection and biopsy specimens. Histopathological samples were well, moderately, and poorly differentiated in 33, 22, and 12 patients, respectively, and the GPC3 expression rate was $63 \%$, 86\%, and $92 \%$,respectively. The median overall survival was $\mathbf{4 9 . 9}$ months (confidence interval (CI): 35.3-64.6 months) for clinical scores 0-1 and 30.7 months (CI: 19.4-41.9 months) for clinical scores $2-3$. This difference was not statistically significant $(P=.06)$ but showed a strong trend. In conclusion, a greater GPC3 expression is associated with a worse HCC prognosis and may be a promising prognostic marker.

\section{INTRODUCTION}

Hepatocellular carcinoma (HCC) is the second most common cause of cancer-related mortality worldwide, and it is the fifth most common cancer in men $(554,000$ cases/year, $7.5 \%$ of total cancer cases) and the ninth in women $(228,000$ cases/year, $3.4 \%$ of total cancer cases). Each year, 745,000 people worldwide die of the disease [1]. Cirrhosis is the greatest single risk factor for HCC, and other risk factors include chronic hepatitis B or C infection, exposure to aflatoxin, alcohol abuse, fatty liver disease, and smoking. HCC is commonly diagnosed at advanced stages, by which time it is usually incurable, unless amenable for surgical intervention [2,3]. Patient prognosis is mainly dependent upon the size and number of tumor nodules, the presence or absence of portal venous invasion, and histopathological differentiation. However, in some cases, the distinction of tumor differentiation is challenging based on histologic grounds alone. Therefore, immunohistochemical (IHC) markers have been studied for prognostication in $\mathrm{HCC}$.

Because $\mathrm{HCC}$ has a distinctive immunohistochemical (IHC) pattern, some IHC markers, such as Glypican-3 (GPC3), hepatocyte paraffin 1 (HepPar1), polyclonal 
CEA (pCEA), MOC-31, CD10, and $\alpha$-fetoprotein (AFP), have been used to differentiate HCC from other tumors and to evaluate prognosis [4-18]. Glypican 3 and HepPar1, for example, are useful in distinguishing high-grade dysplastic nodules from early HCC [19-24]. Well- and moderately-differentiated HCCs stain positive for HepPar1, cytoplasmic thyroid transcription factor-1, glutamine synthetase, GPC3, and cytokeratin 8/18 [21, 22, 25-27]. However, the specificity and sensitivity of these markers is limited [28], and poorly differentiated HCCs may lose immunoreactivity to some IHC markers, including HepPar1, canalicular pCEA, canalicularCD10, and AFP. There is therefore a need for more specific and sensitive immunoreactive hepatocytic markers that can recognize poorly differentiated HCC.

GPC3 shows promise as a prognostic immunohistopathological marker for HCC. GPC3 is a member of the glypican family, which has six members (GPC1-6) and is characterized by heparan sulfate proteoglycans bound to the cell surface by a glycosylphosphatidylinositol anchor [29-34] and which influences cell growth, differentiation, and migration [35-38]. Studies have shown that GPC3's expression rate in non-liver tumors, including mesotheliomas, ovarian tumors, breast tumors, and cholangiocarcinomas, is down-regulated, whereas it is high in HCC [34, 39-44] . Methods employed in assessing GPC3 expressed included immunohistochemistry (IHC), in-situ hybridization (ISH), real-time polymerase chain reaction (RT-PCR) and northern blot. Yamauchi N et al. assessed GPC3 expression in cell membrane and cytoplasm using IHC and categorized cases into either focally positive $(+)$ showing $10-50 \%$ or diffusely positive $(++)$ showing $>50 \%$ expression [43]. However, the relationship between GPC 3 overexpression and prognosis has not yet been clarified in HCC.

A recent study showed that GPC 3 is more sensitive than HepPar1 in detecting HCC [45]. It is especially useful in distinguishing hepatic adenomas or high-grate dysplastic nodules from well-differentiated HCC, in noncirrhotic patients with advanced HCC [20, 43, 46-48].

Firstly, germline GPC3 mutations have been found in patients with Simpson-Golabi-Behmel syndrome, $[31,49-53]$. This syndrome as an X-linked disorder that is characterized by prenatal and postnatal cellular proliferation and that includes visceral and skeletal abnormalities. Notably, some studies have reported GPC3 as a cell proliferation inhibitor and apoptosis inducer, therefore it may play a role in the prognosis of hepatocellular carcinoma [19-24, 54].

GPC3 is an oncofetal protein that is expressed in the placenta and fetal liver, but not in normal hepatic parenchyma or nonmalignant liver tissue, and it is only occasionally and weakly expressed in preneoplastic lesions. However, many studies have shown significantly increased GPC 3 expression in HCC $[5,19,20]$. The goal of the current study was to determine GPC3's staining pattern in $\mathrm{HCC}$ and to define the diagnostic utility of GPC3 in distinguishing early from advanced HCC. We also investigated the potential prognostic value of GPC3 by analyzing the survival rates of patients with low versus high GPC3 expression in HCC tumors and determining whether GPC3 expression was associated with the patients clinicopathologic parameters.

\section{RESULTS}

The detailed baseline demographic characteristics of the $101 \mathrm{HCC}$ patients in our study are summarized in Table 1 . The majority of patients $(62.4 \%)$ were older than 60 years, with a mean age and standard deviation of $63.2 \pm 11.8$ years and a male-to-female ratio of 1.5:1. Risk factors for HCC were hepatitis (35.6\%), alcohol consumption (64.4\%). Twenty-two patients $(21.8 \%)$ had extrahepatic disease (either lymph node involvement or distant metastasis). At the time of initial diagnosis, $62.4 \%$ of patients had an Eastern Cooperative Oncology Group performance status of zero, and the majority of patients had early-stage HCC according to different prognostic scoring and staging systems. Comparison between low clinical score $0-1(N=52)$ and high clinical score $2-3(N=49)$ GPC3 expression showed that there was no statistically significant difference between the two levels based on demographic characteristics, epidemiological parameters, HCC risk factors, clinicopathological characteristics, and baseline treatment modalities (Figure 1).

The Cox proportional hazard models showed that the GPC3 clinical score tended to be a significant independent risk factor for HCC OS. Compared to patients with a GPC3 clinical score of $0-1$, the adjusted HR for patients with a GPC3 clinical score of 2-3 was about 1.5 times higher (adjusted hazard ratio 1.57; 95\% CI, 1.007-2.47; $P=.047$, Table 2).

Futhermore, when the OS of patients who had a clinical score of 0-1 (49.9 months [95\% CI: 35.3-64.6 months]) was compared with that of those with a clinical score of 2-3 (30.7 months [95\% CI: 19.4-41.9 months]), the difference was not statistically significant $(P=0.06))$. However, comparing between varaiotion of the medican OS among patients with low and high clinical score of GPC3 based on the baseline treatment approaches showed that patients with clinical score $0-1$ and treated with surgery have a significantly longer OS compared to patients with higher clinical score 2-3 $(P=.02)$ (Figure 2)

Among the 26 patients with evaluable paired biopsy and resection samples, 15 had the same clinical score for both, even though most patients had a time gap of more than two months between the the acquision of the two samples. Six patients had a higher clinical score for the biopsy than the resection, and five patients had a higher clinical score for the resection than the biopsy (Figure 3 ). The concordance of clinical scores 0 vs. 1 vs. 2 vs. 3 between biopsies and resections was $57.7 \%$ 
Table 1: Demographic characteristics, risk factors, and clinicopathological characteristics of 101 HCC patients

\begin{tabular}{|c|c|c|c|}
\hline \multirow{2}{*}{ Variables } & \multicolumn{3}{|c|}{ HCC patients $(N=101)$} \\
\hline & No. of patients & $\%$ & $95 \%$ CI \\
\hline \multicolumn{4}{|l|}{ Age at diagnosis (years) } \\
\hline Mean ( \pm SD) & $63.2 \pm 11.8$ & & \\
\hline$\leq 60$ & 38 & 37.6 & $0.28-0.48$ \\
\hline$>60$ & 63 & 62.4 & $0.52-0.72$ \\
\hline \multicolumn{4}{|l|}{ Sex } \\
\hline Male & 61 & 60.4 & $0.5-0.7$ \\
\hline Female & 40 & 39.6 & $0.3-0.5$ \\
\hline \multicolumn{4}{|l|}{ Race } \\
\hline White & 74 & 73.3 & $0.64-0.82$ \\
\hline Non-white & 27 & 26.7 & $0.18-0.36$ \\
\hline \multicolumn{4}{|l|}{ Hepatitis status } \\
\hline HCV only & 17 & 16.8 & $0.1-0.26$ \\
\hline HBV only & 13 & 12.9 & $0.07-0.21$ \\
\hline $\mathrm{HCV}$ and $\mathrm{HBV}$ & 6 & 5.9 & $0.02-0.12$ \\
\hline None & 65 & 64.4 & $0.54-0.74$ \\
\hline $\begin{array}{l}\text { Family history of liver } \\
\text { cancer }\end{array}$ & 9 & 8.9 & $0.04-016$ \\
\hline $\begin{array}{l}\text { Family history of other } \\
\text { cancer }\end{array}$ & 73 & 72.3 & $0.62-0.81$ \\
\hline History of other cancers & 20 & 19.8 & $0.13-0.29$ \\
\hline $\begin{array}{l}\text { History of cigarette } \\
\text { smoking }\end{array}$ & 64 & 63.4 & $0.53-0.73$ \\
\hline $\begin{array}{l}\text { History of alcohol } \\
\text { consumption }\end{array}$ & 65 & 64.4 & $0.54-0.74$ \\
\hline Presence of cirrhosis & 54 & 53.5 & $0.43-0.63$ \\
\hline \multicolumn{4}{|l|}{$\begin{array}{l}\text { Performance status } \\
\text { (ECOG) }\end{array}$} \\
\hline $\mathbf{0}$ & 63 & 62.4 & $0.52-0.72$ \\
\hline 1-2 & 34 & 33.7 & $0.25-0.44$ \\
\hline $3-4$ & 4 & 4.0 & $0.01-0.1$ \\
\hline AFP level $\geq 400 \mathrm{ng} / \mathrm{dl}$ & 26 & 25.7 & $0.18-0.35$ \\
\hline $\begin{array}{l}\text { Presence of vascular } \\
\text { invasion }\end{array}$ & 14 & 13.9 & $0.78-0.22$ \\
\hline$>\mathbf{5 0} \%$ tumor involvement $*$ & 10 & 9.9 & $0.05-0.17$ \\
\hline Distant metastasis & 17 & 16.8 & $0.1-0.26$ \\
\hline Lymph node metastasis & 11 & 10.9 & $0.06-0.19$ \\
\hline Multi-nodularity* & 38 & 37.6 & $0.28-0.48$ \\
\hline \multicolumn{4}{|l|}{ Tumor differentiation* } \\
\hline Well-differentiated & 33 & 32.7 & $0.24-0.43$ \\
\hline Moderately differentiated & 22 & 21.8 & $0.14-0.31$ \\
\hline Poorly differentiated & 12 & 11.9 & $0.06-0.2$ \\
\hline \multicolumn{4}{|l|}{ Child-Pugh class } \\
\hline $\mathbf{A}$ & 81 & 80.2 & $0.71-0.87$ \\
\hline B-C & 20 & 19.8 & $0.13-0.29$ \\
\hline \multicolumn{4}{|l|}{ CLIP staging* } \\
\hline Stage 0-2 & 88 & 87.1 & $0.79-0.93$ \\
\hline Stage 3-6 & 9 & 8.9 & $0.04-0.16$ \\
\hline BCLC staging* & & & \\
\hline
\end{tabular}




$\begin{array}{lccc}\begin{array}{l}\text { Stage 0-B } \\ \text { Stage C-D }\end{array} & 45 & 44.6 & \mathbf{0 . 3 5}-\mathbf{0 . 5 5} \\ \text { M staging* } & 55 & 54.5 & \mathbf{0 . 4 4 - 0 . 6 4} \\ \quad \text { Stage I-II } & 63 & 64.3 & \mathbf{0 . 5 2 - 0 . 7 2} \\ \text { Stage IIIA-IIIB } & 35 & 35.7 & \mathbf{0 . 2 5}-\mathbf{0 . 4 5} \\ \text { uda staging* } & & & \\ \text { Stage I } & 68 & 67.3 & \mathbf{0 . 5 7 - 0 . 7 6} \\ \text { Stage II-III } & 29 & 28.7 & \mathbf{0 . 2}-\mathbf{0 . 3 9} \\ \text { seline treatment } & & & \\ \text { Surgery or transplant } & 56 & 55.4 & \mathbf{0 . 4 5}-\mathbf{0 . 6 5} \\ \text { Local therapy } & 20 & 19.8 & \mathbf{0 . 1 3}-\mathbf{0 . 2 9} \\ \text { Systemic therapy } & 18 & 17.8 & \mathbf{0 . 1 1}-\mathbf{0 . 2 7} \\ \text { Best supportive care } & 7 & 6.9 & \mathbf{0 . 0 3}-\mathbf{0 . 1 4}\end{array}$

Abbreviations: AFP, alpha fetoprotein; BCLC, Barcelona Clinic Liver Cancer; CLIP, Cancer of the Liver Italian Program; CI, confidence interval; ECOG, Eastern Cooperative Oncology Group; HBV, hepatitis B virus; HCV, hepatitis C virus; SD, standard deviation; TNM, tumor-node-metastasis.

*Some data are missing: $>50 \%$ tumor involvement; $N=5$ due to unavailable radiology report, Multi-nodularity; $N=4$ due to previous surgery, Tumor differentiation; $N=34$ diagnosed as HCC but the grade of differentiation was not detected, CLIP; $N=4$ due to unavailable information about tumor morphology, BCLC; $N=1$ due to unavailable information about tumor nodularity, TNM stage; $N=3$ due to unavailable information about tumor nodularity and tumor size, OKUDA; $N=4$ due to unavailable information about $\%$ of liver occupied by the tumor.

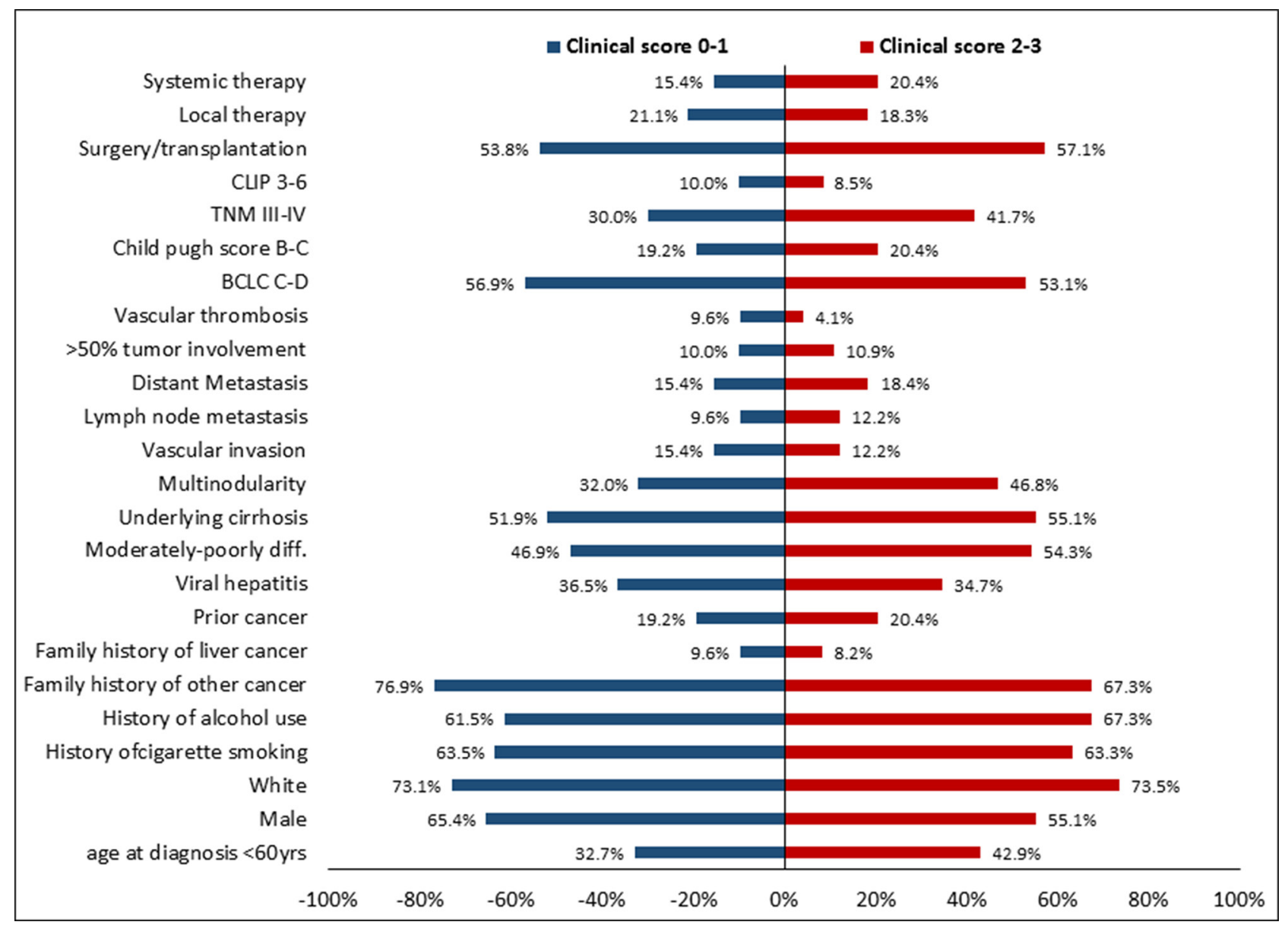

Figure 1: Comparison of risk factors, epidemiological parameters, demographic characteristics, and clinicopathological parameters between patients with a clinical score of $0-1$ and those with a clinical score of 2-3. 
Table 2: Adjusted hazard ratios and 95\% confidence intervals for glypican-3 (GPC3) clinical score and other demographic and clinicopathological characteristics and risk factors

\begin{tabular}{|c|c|c|c|c|}
\hline \multirow{3}{*}{$\begin{array}{r}\text { Parameters } \\
\text { GPC3 clinical score* }\end{array}$} & & Adjusted H & $95 \% \mathrm{CI}$ & $P$ value \\
\hline & $0-1$ & \multicolumn{2}{|c|}{1 (Reference) } & \\
\hline & $2-3$ & 1.57 & $1.007-2.47$ & .047 \\
\hline \multirow[t]{2}{*}{ Age } & $\leq 60$ & \multicolumn{2}{|c|}{1 (Reference) } & \\
\hline & $>60$ & 1.01 & $0.99-1.03$ & .32 \\
\hline \multirow[t]{2}{*}{ Sex } & Female & \multicolumn{2}{|c|}{1 (Reference) } & \\
\hline & Male & 1.07 & $0.69-1.67$ & .76 \\
\hline \multirow[t]{2}{*}{ Race } & Non-white & \multicolumn{2}{|c|}{1 (Reference) } & \\
\hline & White & 0.9 & $0.54-1.62$ & .81 \\
\hline \multirow[t]{2}{*}{ Vascular invasion } & No & \multicolumn{2}{|c|}{1 (Reference) } & \\
\hline & Yes & 1.18 & $0.59-2.37$ & .64 \\
\hline \multirow[t]{2}{*}{ Lymph node metastasis } & No & \multicolumn{2}{|c|}{1 (Reference) } & \\
\hline & Yes & 1.44 & $0.61-3.44$ & .4 \\
\hline \multirow[t]{2}{*}{ Distant metastasis } & No & \multicolumn{2}{|c|}{1 (Reference) } & \\
\hline & Yes & 1.88 & $0.84-4.2$ & .12 \\
\hline \multirow[t]{2}{*}{$\%$ of liver occupied by tumor } & $\leq 50 \%$ & \multicolumn{2}{|c|}{1 (Reference) } & \\
\hline & $>50 \%$ & 0.8 & $0.39-1.65$ & .55 \\
\hline \multirow[t]{3}{*}{ BCLC } & 0 & \multicolumn{2}{|c|}{1 (Reference) } & \\
\hline & A-B & 0.59 & $0.3-1.16$ & .12 \\
\hline & C-D & 0.74 & $0.42-1.28$ & .28 \\
\hline \multirow[t]{2}{*}{ Treatment } & Non-surgical & \multicolumn{2}{|c|}{1 (Reference) } & \\
\hline & Surgery & 0.5 & $0.31-0.79$ & . 003 \\
\hline
\end{tabular}

Abbreviations: BCLC, Barcelona Clinic Liver Cancer; CI, confidence interval; HR, hazard ratio.

*Adjusted hazard ratio of GPC3 clinical score after controlling for confounding factors such as age, sex, race, vascular invasion, lymph node involvement, distant metastasis, \% of liver occupied by tumor, BCLC staging system, and HCC treatment modalities.

(95\% CI: 39.0-74.5). The concordance of clinical scores $0-1$ vs. $2-3$ between biopsies and resections was $80.8 \%$ (95\% CI: 62.1-91.5).

\section{DISCUSSION}

Our current study indicates that higher GPC3 expression level in $\mathrm{HCC}$ is a risk factor for shorter OS. GPC3 expression may also be associated with histopathologic differentiation grade and advanced clinicopathologic features, but these findings were not significant. Consistent with our findings, Yamauchi et al. found that levels of GPC3 expression in poorly differentiated tumor cells were higher than those in moderately and well differentiated tumor cells. GPC3 was expressed in $78 \%$ (14 of 18) of well-differentiated tumors, $83 \%$ (24 of 29 ) of moderately-differentiated tumors, and 100\% (9 of 9) of poorly differentiated tumors, while the size of the HCC was not related to the level of GPC3 expression. In the same study, GPC3 expression was negative in sarcomatoid HCC, carcinoid tumors, and cholangiocarcinomas [43]. The reported sensitivity of GPC3 for HCC in the literature ranges from $75 \%$ to $100 \%$, and in large-scale trials it ranges from $75 \%$ to $85 \%$ [26, 43, 47, 55-57].

Our study showed a large difference in OS between patients with a GPC 3 clinical score of $0-1$ and patients with GPC3 clinical score of 2-3. However, it wasn't statistically significant there is strong trend toward better OS. The median OS was 49.9 months (95\% CI: 35.3-64.6 months) for GPC3 clinical score $0-1$ and 30.7 months $(95 \%$ CI: 19.4-41.9 months) for GPC3 clinical score 2-3 $(P=0.06)$ (Figure 3). Furthermore, we found a correlation between GPC3 expression rate and vascular invasion, $>50 \%$ tumor involvement in the liver, lymph nodes involvement, alcohol use, cigarette smoking, race, gender, age, or stage (CLIP,TNM,BCLC and CTP). However, due to small sample size in our single institution study, this limitation may account for the lack of statistical significance in some of the correlation analyzed . 

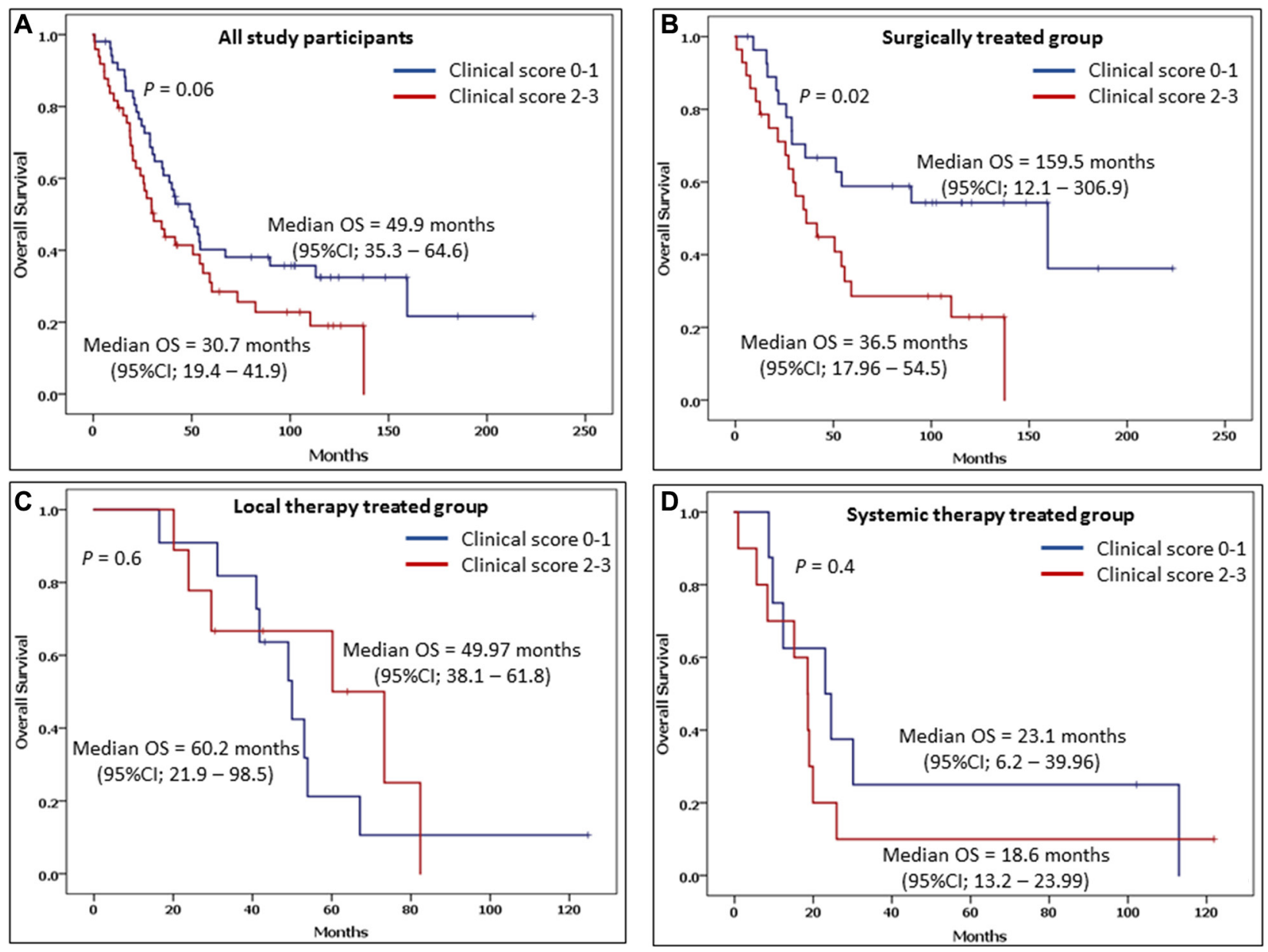

Figure 2: Overall survival (OS) and the $95 \%$ confidence interval (CI) in patients with clinical scores of $0-1$ and 2-3 include A) among all study participants, B) among surgically treated patients, C) among local therapy treated patients, and D) among systemic therapy treated patients.

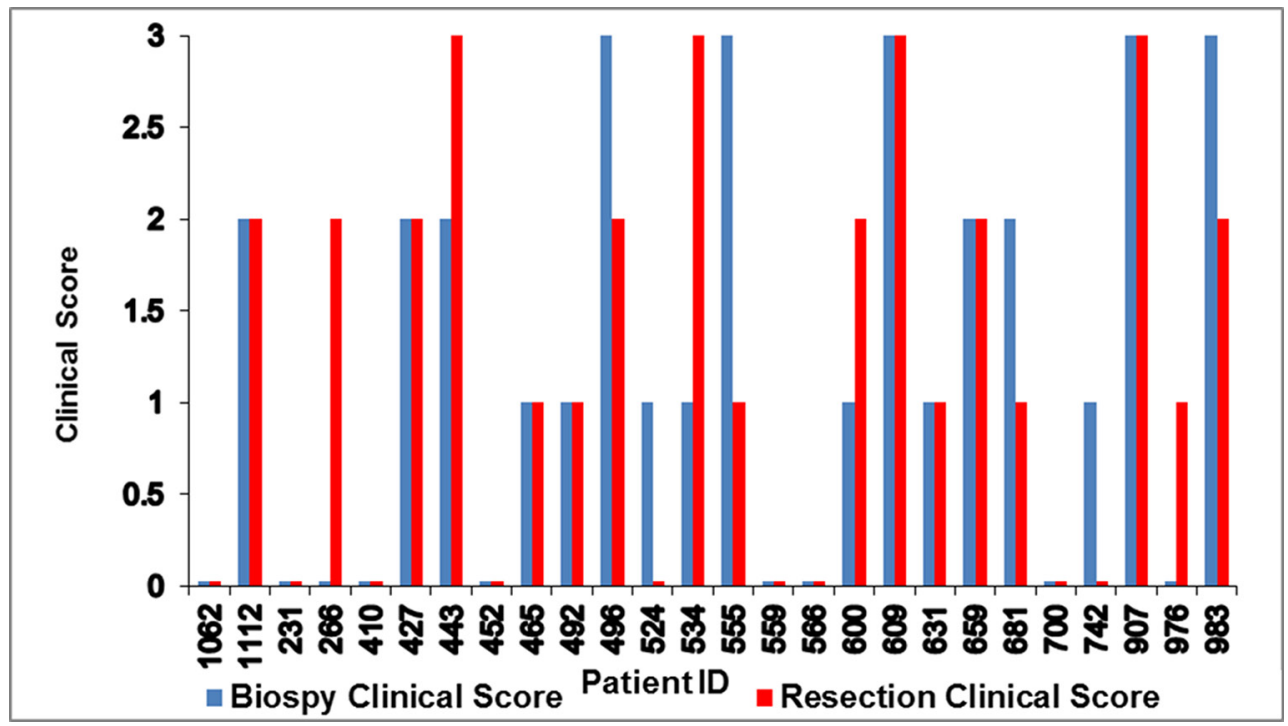

Figure 3: Variations in paired biopsy and resection clinical scores for 26 patients. 
Additionally, we compared the expression of GPC3 in 26 patients who had both biopsy and resection, the majority of samples were concordant even though most of them collected after a time gap of over 2 months between the procedures. Based on this result, our study indicated that biopsies may provide reliable information about GPC3 expression. However, due to the limitations of our study, including a small number of samples, a time gap between biopsy and resection, and the effects of therapy on tissue nature, this result needs to be confirmed by future well-designed trials.

GPC3 expression and staining is diagnostically important for fibrolamellar HCC, which differs clinically, histologically, molecularly, and prognostically from conventional HCC and which typically occurs in young patients without cirrhosis. Elevation of AFP is uncommon and immunohistochemistry for AFP is generally negative in fibrolamellar HCC [58-62]. In contrast, a few trials have shown that the disease expresses and stains with GPC3, although, unlike in conventional HCC and especially poorly differentiated HCC the expression rate is not significant $[5,45]$.

Some studies have indicated that serum GPC3, in combination with AFP, improves diagnostic accuracy and sensitivity for early HCC [63-65]. AFP is the most commonly used serum marker for the diagnosis and detection of HCC. At a cutoff value of $20 \mathrm{ng} / \mathrm{mL}$ of serum, AFP shows a $60 \%-80 \%$ sensitivity in detecting tumors [66-69] that decreases to about $40 \%$ for the detection of tumors that are smaller than $3 \mathrm{~cm}$ [68] .Interestingly, GPC3 level is more frequently elevated than AFP level $(88 \%$ versus $55 \%)$ in patients with liver cancer, and especially in those with HCC tumors $<3 \mathrm{~cm}(77 \%$ versus 43\%) [70]. Thus, after independent validation, GPC3 immunoassays may be useful in diagnosing HCC, as GPC3 has been shown to have serological sensitivity and specificity of $53 \%$ and $95 \%$, respectively [64].

Our study results suggest that the GPC 3 expression rate could be a promising prognostic marker for HCC. However, large-scale, independent validation studies are warranted to confirm and further define the prognostic role and implications of GPC3 in this disease.

\section{MATERIALS AND METHODS}

\section{Study design and population}

Our current investigation is part of an ongoing, hospital-based, case-control study that was approved by The University of Texas MD Anderson Cancer Center Institutional Review Board. Written informed consent was obtained from each study participant.

We searched our patients database and identified 101 patients with histologically confirmed HCC treated from March 1996 to September 2012. Seven patients hadbiopsy specimens only, 31 patients had resection specimens only, and 26 patients had both resection and biopsy specimens. The following clinical variables were recorded at the time of diagnosis and retrieved from the patients' medical records: patient demographics, HCC risk factors (including cirrhosis), tumor characteristics (such as histologic differentiation, vascular invasion, extrahepatic metastasis, size and number of tumor nodules, and the percentage of the liver occupied by tumor), HCC treatment regimens and modalities, and survival. We also collected information about disease stage using various HCC staging systems, including Barcelona Clinic Liver Cancer (BCLC), Cancer of the Liver Italian Program (CLIP); tumor-node-metastasis (TNM), and OKUDA.

We retrieved the patients' paraffin-embedded tissue specimens Unstained sections, and IHC was performed at Ventana Medical Systems, Inc. (VMSI, Tucson, AZ). IHC procedures for GPC3, including antigen recovery, antibody incubation, and antibody detection, were done in the college of American pathologist (CAP) and Cliical Laboratory Improvement Act (CLIA) accredited certified laboratory. Tissue sections were stained using anti-Glypican 3 mouse monoclonal primary antibody (clone GC33, Ventana Medical Systems, Inc. Tucson, AZ) on BenchMark ULTRA to detect membrane and cytoplasmic expression. Heat-induced epitope retrieval was used followed by incubation of the primary antibody for $32 \mathrm{~min}$ at $36^{\circ} \mathrm{C}$. Immunodetection was accomplished with ultraView Universal DAB Detection Kit. Appropriate positive and negative controls were included for each stain.

Based on GPC3 staining intensity and the percentage of stained tumor cells, patients were classified into one of four clinical score categories (Figure 4) according to the criteria described in Table 3. During scoring, pathologists were blinded to specimen and clinical details.

\section{Statistical methods}

Stata software (Stata Corp, College Station, TX) was used for statistical analysis. Univariate analysis was done using the $\mathrm{X}^{2}$ or Fisher exact test for categorical variables, and the Kruskal-Wallis test was used for continuous variables for all 101 patients and for comparison between low GPC3 expression (clinical score $0-1$ ) and high GPC3 expression (clinical score 2-3). To identify independent prognostic factors for overall survival (OS), adjusted hazard ratios (HRs) and 95\% confidence intervals (CIs) were calculated using Cox proportional hazard models after adjusting for confounding factors such as age, sex, race, vascular invasion, lymph node involvement, distant metastasis, volume percentage of liver occupied by tumor, BCLC staging system, and HCC treatment modalities. The clinical score HR was adjusted for age, sex, race, vascular invasion, distant metastasis, lymph node involvement, the percentage of the liver occupied by the tumor(s), the Barcelona Clinic Liver Cancer (BCLC) 


\begin{tabular}{ll}
\hline Score & Description \\
\hline 0 & Absent membranous staining \\
& Cytoplasmic staining of any intensity in $<10 \%$ of tumor cells \\
1 & Membranous staining of any intensity in $<10 \%$ of tumor cells, and/or \\
& Cytoplasmic staining of any intensity in $>10 \%$ of tumor cells (note that strong cytoplasmic staining, if present, \\
& must be in $<50 \%$ of tumor cells) \\
& Weak to moderate membrane staining in $\geq 10 \%$ of tumor cells (note that strong membrane staining, if present, \\
& must be in $<10 \%$ of tumor cells), and/or \\
& Cytoplasmic staining of any intensity in $>10 \%$ of tumor cells (note that strong cytoplasmic staining, if present, \\
& must be in $<50 \%$ of tumor cells) \\
& Strong membrane staining in $>10 \%$ of tumor cells with or without cytoplasmic staining, or \\
& Strong cytoplasmic staining in $\geq 50 \%$ of tumor cells \\
\hline
\end{tabular}

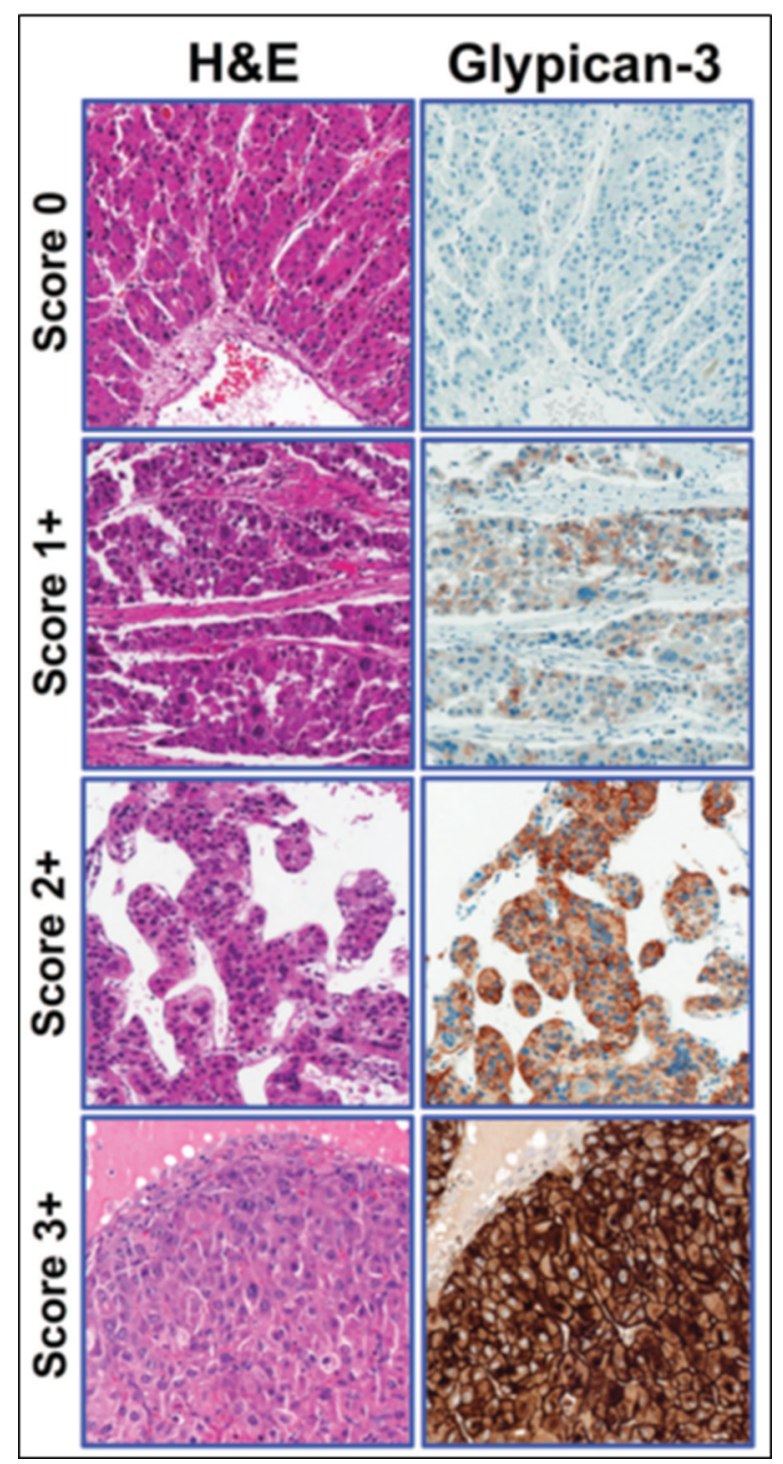

Figure 4: Hepatocellular carcinoma tissue samples showing the correlation between staining and clinical score categories. Left panel: representative examples of hematoxylin and eosin (H\&E)-stained HCC tumors. Right panel: representative examples of Glypican-3-stained HCC tumors. The immunohistochemical scores range from 0 (negative) to $3+$. 
staging system, and HCC treatment modalities. Survival curves were generated by the Kaplan-Meier method, and the statistical significance of differences was determined according to the log-rank test. A $P$ value of .05 was considered statistically significant.

\section{ACKNOWLEDGMENTS}

Editorial assistance was provided by Laura L. Russell of The University of Texas MD Anderson Cancer Center's Department of Scientific Publications.

\section{CONFLICTS OF INTEREST}

The authors declare no conflicts of interest.

\section{GRANT SUPPORT} Co., LTD.

This study was supported by Chugai Pharmaceutical

\section{REFERENCES}

1. Ferlay J, Soerjomataram I, Dikshit R, Eser S, Mathers C, Rebelo M, Parkin DM, Forman D, Bray F. Cancer incidence and mortality worldwide: sources, methods and major patterns in GLOBOCAN 2012. Int J Cancer. 2015; 136:E359-386.

2. Yeh $\mathrm{CN}$, Lee WC, Chen MF. Hepatic resection and prognosis for patients with hepatocellular carcinoma larger than $10 \mathrm{~cm}$ : two decades of experience at Chang Gung memorial hospital. Ann Surg Oncol. 2003; 10:1070-1076.

3. Poon RT, Fan ST, Wong J. Selection criteria for hepatic resection in patients with large hepatocellular carcinoma larger than $10 \mathrm{~cm}$ in diameter. J Am Coll Surg. 2002; 194:592-602.

4. Borscheri N, Roessner A, Rocken C. Canalicular immunostaining of neprilysin (CD10) as a diagnostic marker for hepatocellular carcinomas. Am J Surg Pathol. 2001; 25:1297-1303.

5. Wang L, Vuolo M, Suhrland MJ, Schlesinger K. HepPar1, MOC-31, pCEA, mCEA and CD10 for distinguishing hepatocellular carcinoma vs. metastatic adenocarcinoma in liver fine needle aspirates. Acta Cytol. 2006; 50:257-262.

6. Bedrossian $\mathrm{CW}$, Davila RM, Merenda G. Immunocytochemical evaluation of liver fine-needle aspirations. Arch Pathol Lab Med. 1989; 113:1225-1230.

7. Carrozza MJ, Calafati SA, Edmonds PR. Immunocytochemical localization of polyclonal carcinoembryonic antigen in hepatocellular carcinomas. Acta Cytol. 1991; 35:221-224.

8. Christensen WN, Boitnott JK, Kuhajda FP. Immunoperoxidase staining as a diagnostic aid for hepatocellular carcinoma. Modern pathology Mod Pathol. 1989; 2:8-12.
9. Fischer HP, Altmannsberger M, Weber K, Osborn M. Keratin polypeptides in malignant epithelial liver tumors. Differential diagnostic and histogenetic aspects. Am J Pathol. 1987; 127:530-537.

10. Fucich LF, Cheles MK, Thung SN, Gerber MA, Marrogi AJ. Primary vs metastatic hepatic carcinoma. An immunohistochemical study of 34 cases. Arch Pathol Lab Med. 1994; 118:927-930.

11. Kakar S, Muir T, Murphy LM, Lloyd RV, Burgart LJ. Immunoreactivity of Hep Par 1 in hepatic and extrahepatic tumors and its correlation with albumin in situ hybridization in hepatocellular carcinoma. Am J Clin Pathol. 2003; 119:361-366.

12. Leong AS, Sormunen RT, Tsui WM, Liew CT. Hep Par 1 and selected antibodies in the immunohistological distinction of hepatocellular carcinoma from cholangiocarcinoma, combined tumours and metastatic carcinoma. Histopathology. 1998; 33:318-324.

13. Ma CK, Zarbo RJ, Frierson HF Jr, Lee MW. Comparative immunohistochemical study of primary and metastatic carcinomas of the liver. Am J Clin Pathol. 1993; 99:551-557.

14. Maeda T, Kajiyama K, Adachi E, Takenaka K, Sugimachi K, Tsuneyoshi M. The expression of cytokeratins 7, 19, and 20 in primary and metastatic carcinomas of the liver. Mod Pathol. 1996; 9:901-909.

15. Niemann TH, Hughes JH, De Young BR. MOC-31 aids in the differentiation of metastatic adenocarcinoma from hepatocellular carcinoma. Cancer. 1999; 87:295-298.

16. Porcell AI, De Young BR, Proca DM, Frankel WL. Immunohistochemical analysis of hepatocellular and adenocarcinoma in the liver: MOC31 compares favorably with other putative markers.Mod Pathol. 2000; 13:773-778.

17. Van Eyken P, Sciot R, Paterson A, Callea F, Kew MC, Desmet VJ. Cytokeratin expression in hepatocellular carcinoma: an immunohistochemical study. Hum Pathol. 1988; 19:562-568.

18. Chan ES, Yeh MM. The use of immunohistochemistry in liver tumors. Clin Liver Dis. 2010; 14:687-703.

19. Di Tommaso L, Franchi G, Park YN, Fiamengo B, Destro A, Morenghi E, Montorsi M, Torzilli G, Tommasini M, Terracciano L, Tornillo L, Vecchione R, Roncalli M. Diagnostic value of HSP70, glypican 3, and glutamine synthetase in hepatocellular nodules in cirrhosis. Hepatology. 2007; 45:725-734.

20. Durnez A, Verslype C, Nevens F, Fevery J, Aerts R, Pirenne J, Lesaffre E, Libbrecht L, Desmet V, Roskams T. The clinicopathological and prognostic relevance of cytokeratin 7 and 19 expression in hepatocellular carcinoma. A possible progenitor cell origin. Histopathology. 2006; 49:138-151.

21. Roskams T, Kojiro M. Pathology of early hepatocellular carcinoma: conventional and molecular diagnosis. Semin Liver Dis. 2010; 30:17-25.

22. Saad RS, Luckasevic TM, Noga CM, Johnson DR, Silverman JF, Liu YL. Diagnostic value of HepPar1, pCEA, CD10, and CD34 expression in separating hepatocellular 
carcinoma from metastatic carcinoma in fine-needle aspiration cytology. Diagn Cytopathol. 2004; 30:1-6.

23. Uenishi T, Kubo S, Yamamoto T, Shuto T, Ogawa M, Tanaka H, Tanaka S, Kaneda K, Hirohashi K. Cytokeratin 19 expression in hepatocellular carcinoma predicts early postoperative recurrence. Cancer Sci. 2003; 94:851-857.

24. Yoneda N, Sato Y, Kitao A, Ikeda H, Sawada-Kitamura S, Miyakoshi M, Harada K, Sasaki M, Matsui O, Nakanuma Y. Epidermal growth factor induces cytokeratin 19 expression accompanied by increased growth abilities in human hepatocellular carcinoma. Lab Invest. 2011; 91:262-272.

25. Lei JY, Bourne PA, diSant'Agnese PA, Huang J. Cytoplasmic staining of TTF-1 in the differential diagnosis of hepatocellular carcinoma vs cholangiocarcinoma and metastatic carcinoma of the liver. Am J Clin Pathol. 2006; 125:519-525.

26. Nakatsura T, Yoshitake Y, Senju S, Monji M, Komori H, Motomura Y, Hosaka S, Beppu T, Ishiko T, Kamohara H, Ashihara H, Katagiri T, Furukawa Y, et al. Glypican-3, overexpressed specifically in human hepatocellular carcinoma, is a novel tumor marker. Biochem Biophys Res Commun. 2003; 306:16-25.

27. Butler SL, Dong H, Cardona D, Jia M, Zheng R, Zhu H, Crawford JM, Liu C. The antigen for Hep Par 1 antibody is the urea cycle enzyme carbamoyl phosphate synthetase 1 . Laboratory investigation; Lab Invest. 2008; 88:78-88.

28. Chu PG, Ishizawa S, Wu E, Weiss LM. Hepatocyte antigen as a marker of hepatocellular carcinoma: an immunohistochemical comparison to carcinoembryonic antigen, CD10, and alpha-fetoprotein. Am J Surg Pathol. 2002; 26:978-988.

29. Bernfield M, Gotte M, Park PW, Reizes O, Fitzgerald ML, Lincecum J, Zako M. Functions of cell surface heparan sulfate proteoglycans. Annu Rev Biochem. 1999; 68:729-777.

30. Filmus J. Glypicans in growth control and cancer. Glycobiology. 2001; 11:19R-23R.

31. Filmus J, Church JG, Buick RN. Isolation of a cDNA corresponding to a developmentally regulated transcript in rat intestine. Mol Cell Biol. 1988; 8:4243-4249.

32. Filmus J, Selleck SB. Glypicans: proteoglycans with a surprise. J Clin Invest. 2001; 108:497-501.

33. Filmus J, Song H, Shi W, Duenas Gonzalez A, Kaya M, Cano-Gauci D. Glypican-3 is a novel inhibitor of insulin-like growth factor signaling. Medicina (B Aires). 1999; 59:546.

34. Murthy SS, Shen T, De Rienzo A, Lee WC, Ferriola PC, Jhanwar SC, Mossman BT, Filmus J, Testa JR. Expression of GPC3, an X-linked recessive overgrowth gene, is silenced in malignant mesothelioma. Oncogene. 2000; 19:410-416.

35. Farooq M, Hwang SY, Park MK, Kim JC, Kim MK, Sung YK. Blocking endogenous glypican-3 expression releases Hep 3B cells from G1 arrest. Mol Cells. 2003; 15:356-360.

36. Gonzalez AD, Kaya M, Shi W, Song H, Testa JR, Penn LZ, Filmus J. OCI-5/GPC3, a glypican encoded by a gene that is mutated in the Simpson-Golabi-Behmel overgrowth syndrome, induces apoptosis in a cell line-specific manner. J Cell Biol. 1998; 141:1407-1414.
37. Li M, Choo B, Wong ZM, Filmus J, Buick RN. Expression of OCI-5/glypican 3 during intestinal morphogenesis: regulation by cell shape in intestinal epithelial cells. Exp Cell Res. 1997; 235:3-12.

38. Song HH, Shi W, Filmus J. OCI-5/rat glypican-3 binds to fibroblast growth factor-2 but not to insulin-like growth factor-2. J Biol Chem. 1997; 272:7574-7577.

39. Hsu HC, Cheng W, Lai PL. Cloning and expression of a developmentally regulated transcript MXR7 in hepatocellular carcinoma: biological significance and temporospatial distribution. Cancer Res. 1997; 57:5179-5184.

40. Lin H, Huber R, Schlessinger D, Morin PJ. Frequent silencing of the GPC3 gene in ovarian cancer cell lines. Cancer Res. 1999; 59:807-810.

41. Man XB, Tang L, Zhang BH, Li SJ, Qiu XH, Wu MC, Wang HY. Upregulation of Glypican-3 expression in hepatocellular carcinoma but downregulation in cholangiocarcinoma indicates its differential diagnosis value in primary liver cancers. Liver Int. 2005; 25:962-966.

42. Xiang YY, Ladeda V, Filmus J. Glypican-3 expression is silenced in human breast cancer. Oncogene. 2001; 20:7408-7412.

43. Yamauchi N, Watanabe A, Hishinuma M, Ohashi K, Midorikawa Y, Morishita Y, Niki T, Shibahara J, Mori M, Makuuchi M, Hippo Y, Kodama T, Iwanari H, et al. The glypican 3 oncofetal protein is a promising diagnostic marker for hepatocellular carcinoma. Mod Pathol. 2005; 18:1591-1598.

44. Zhu ZW, Friess H, Wang L, Abou-Shady M, Zimmermann A, Lander AD, Korc M, Kleeff J, Buchler MW. Enhanced glypican-3 expression differentiates the majority of hepatocellular carcinomas from benign hepatic disorders. Gut. 2001; 48:558-564.

45. Shafizadeh N, Ferrell LD, Kakar S. Utility and limitations of glypican-3 expression for the diagnosis of hepatocellular carcinoma at both ends of the differentiation spectrum. Mod Pathol. 2008; 21:1011-1018.

46. Coston WM, Loera S, Lau SK, Ishizawa S, Jiang Z, Wu CL, Yen Y, Weiss LM, Chu PG. Distinction of hepatocellular carcinoma from benign hepatic mimickers using Glypican-3 and CD34 immunohistochemistry. Am J Surg Pathol. 2008; 32:433-444.

47. Wang XY, Degos F, Dubois S, Tessiore S, Allegretta M, Guttmann RD, Jothy S, Belghiti J, Bedossa P, Paradis V. Glypican-3 expression in hepatocellular tumors: diagnostic value for preneoplastic lesions and hepatocellular carcinomas. Hum Pathol. 2006; 37:1435-1441.

48. Zhang L, Liu H, Sun L, Li N, Ding H, Zheng J. Glypican-3 as a potential differential diagnosis marker for hepatocellular carcinoma: a tissue microarray-based study. Acta Histochem. 2012; 114:547-552.

49. Stipp CS, Litwack ED, Lander AD. Cerebroglycan: an integral membrane heparan sulfate proteoglycan that is unique to the developing nervous system and expressed specifically during neuronal differentiation. J Cell Biol. 1994; 124:149-160. 
50. David G, Lories V, Decock B, Marynen P, Cassiman JJ, Van den Berghe H. Molecular cloning of a phosphatidylinositolanchored membrane heparan sulfate proteoglycan from human lung fibroblasts. J Cell Biol. 1990; 111:3165-3176.

51. Veugelers M, Vermeesch J, Reekmans G, Steinfeld R, Marynen P, David G. Characterization of glypican-5 and chromosomal localization of human GPC5, a new member of the glypican gene family. Genomics. 1997; 40:24-30.

52. Paine-Saunders S, Viviano BL, Saunders S. GPC6, a novel member of the glypican gene family, encodes a product structurally related to GPC4 and is colocalized with GPC5 on human chromosome 13. Genomics. 1999; 57:455-458.

53. Watanabe K, Yamada H, Yamaguchi Y. K-glypican: a novel GPI-anchored heparan sulfate proteoglycan that is highly expressed in developing brain and kidney. J Cell Biol. 1995; 130:1207-1218.

54. Cano-Gauci DF, Song HH, Yang H, McKerlie C, Choo B, Shi W, Pullano R, Piscione TD, Grisaru S, Soon S, Sedlackova L, Tanswell AK, Mak TW, et al. Glypican-3deficient mice exhibit developmental overgrowth and some of the abnormalities typical of Simpson-Golabi-Behmel syndrome. J Cell Biol. 1999; 146:255-264.

55. Filmus J, Capurro M. Glypican-3: a marker and a therapeutic target in hepatocellular carcinoma. FEBS J. 2013; 280:2471-2476.

56. Libbrecht L, Severi T, Cassiman D, Vander Borght S, Pirenne J, Nevens F, Verslype C, van Pelt J, Roskams T. Glypican-3 expression distinguishes small hepatocellular carcinomas from cirrhosis, dysplastic nodules, and focal nodular hyperplasia-like nodules. Am J Surg Pathol. 2006; 30:1405-1411.

57. Kandil D, Leiman G, Allegretta M, Trotman W, Pantanowitz L, Goulart R, Evans M. Glypican-3 immunocytochemistry in liver fine-needle aspirates : a novel stain to assist in the differentiation of benign and malignant liver lesions. Cancer. 2007; 111:316-322.

58. Ward SC, Waxman S. Fibrolamellar carcinoma: a review with focus on genetics and comparison to other malignant primary liver tumors. Semin Liver Dis. 2011; 31:61-70.

59. Li W, Tan D, Zenali MJ, Brown RE. Constitutive activation of nuclear factor-kappa B (NF-kB) signaling pathway in fibrolamellar hepatocellular carcinoma. Int J Clin Exp Pathol. 2010; 3:238-243.
60. Honeyman JN, Simon EP, Robine N, Chiaroni-Clarke R, Darcy DG, Lim, II, Gleason CE, Murphy JM, Rosenberg BR, Teegan L, Takacs CN, Botero S, Belote R, et al. Detection of a recurrent DNAJB1-PRKACA chimeric transcript in fibrolamellar hepatocellular carcinoma. Science. 2014; 343:1010-1014.

61. Ruffin MTt. Fibrolamellar hepatoma. Am J Gastroenterol. 1990; 85:577-581.

62. Berman MA, Burnham JA, Sheahan DG. Fibrolamellar carcinoma of the liver: an immunohistochemical study of nineteen cases and a review of the literature. Hum Pathol. 1988; 19:784-794.

63. Tangkijvanich P, Chanmee T, Komtong S, Mahachai V, Wisedopas N, Pothacharoen P, Kongtawelert P. Diagnostic role of serum glypican-3 in differentiating hepatocellular carcinoma from non-malignant chronic liver disease and other liver cancers. J Gastroenterol Hepatol. 2010; 25:129-137.

64. Capurro M, Wanless IR, Sherman M, Deboer G, Shi W, Miyoshi E, Filmus J. Glypican-3: a novel serum and histochemical marker for hepatocellular carcinoma. Gastroenterology. 2003; 125:89-97.

65. Ozkan H, Erdal H, Kocak E, Tutkak H, Karaeren Z, Yakut M, Koklu S. Diagnostic and prognostic role of serum glypican 3 in patients with hepatocellular carcinoma. J Clin Lab Anal. 2011; 25:350-353.

66. Chan D SS. Tumor markers. In: Burtis CA AA, ed. Tietz textbook of clinical chemistry. Philadelphia: Saunders. 1999; 722-749.

67. Johnson PJ. The role of serum alpha-fetoprotein estimation in the diagnosis and management of hepatocellular carcinoma. Clin Liver Dis. 2001; 5:145-159.

68. Taketa K. Alpha-fetoprotein: reevaluation in hepatology. Hepatology. 1990; 12:1420-1432.

69. Trevisani F, D'Intino PE, Morselli-Labate AM, Mazzella G, Accogli E, Caraceni P, Domenicali M, De Notariis S, Roda E, Bernardi M. Serum alpha-fetoprotein for diagnosis of hepatocellular carcinoma in patients with chronic liver disease: influence of HBsAg and anti-HCV status. J Hepatol. 2001; 34:570-575.

70. Hsu LS, Tsou AP, Chi CW, Lee CH, Chen JY. Cloning, expression and chromosomal localization of human $\mathrm{Ca} 2+/$ calmodulin-dependent protein kinase kinase. J Biomed Sci. 1998; 5:141-149. 